\title{
Litteratur om och av Elie Wiesel
}

\author{
Karl-Johan Illman
}

Abo

Den främsta platsen bland holocaust-forfattarna har sedan 60-talet intagits av Elie Wiesel. Det var han som lanserade termen "holocaust" ("brännoffer") för förintelsen av de europeiska judarna under andra världskriget, men beklagar sedermera den framgången: termen har blivit för populär och för billig för att kunna uttrycka det den var avsedd för. ${ }^{1}$ Detta äger säkert sin riktighet. Själv har Wiesel inte devaluerat sitt budskap och det har inte heller förlorat något av sin aktualitet. Trettio år efter publiceringen av La Nuit har hans författarskap vuxit ut till universella dimensioner. Idag (han fyller 60 år den 30.9. 1988) betraktas han därtill med rätta som en av vår tids stora fredskämpar, för vilket han ju även belönades med Nobels fredspris år 1986.

Denna recensionsartikel behandlar tre nyare arbeten om Wiesel, en källutgåva och en bok av honom, dvs hans senaste roman. Artikeln åtföljs av en "nordisk" bibliografi.

\section{Ett teologiskt perspektiv}

Intresset för de teologiska implikationerna av holocaust och for Wiesels vittnesbörd vaknade i mitten av 60-talet, främst i Förenta Staterna, men snart också t.ex. i Förbundsrepubliken Tyskland och i Frankrike. ${ }^{2}$ Sedan dess har det blivit allt vanligare med hänvisningar till denna besvārande, ja plågsamma, kontext för teologin. Den katolske teologen J.B. Metz gick så långt som att säga, att man inte borde bedriva någon (kristen) teologi som förblir oberörd av Auschwitz. ${ }^{3}$ In i detta sammanhang ställer sig nu också Robert McAfee Brown, professor i teologi och etik vid The Pacific School of Religion (Berkeley) och medlem av U.S. Holocaust Memorial Council, som 1978 grundades av president Carter med Elie Wiesel som första ordförande. Hans bok Elie Wiesel: Messenger to All Humanity ${ }^{4}$ förenar en interpretation av Wiesels skrifter (främst romanerna) med en teologisk nyorientering på några viktiga punkter.

Intressant och i akademiska sammanhang måhända problematiskt är Browns beskrivning av sin approach i slutet av sitt forord: "This is not a 'critical' appraisal of Wiesel, and I make no apologies for the fact. My concern has been to expound him clearly enough and sympathetically enough so that readers can go on to confront him at first hand. Then they can, if they wish, engage in critique. The critique, for me, has been the other way around. Elie Wiesel has forced me to reevaluate a whole lifetime of assumptions. Let the pupil be content to acknowledge a debt to his rebbe." (s. xii). Wiesels verk är nog objekt för Browns studie, men så att det ifrågasätter hans position, inte tvärtom.

Brown ägnar sitt forsta kapitel bl.a. åt att fastställa Wiesels roll som interpret av holocaust och dess betydelse for vår tid. Han menar att Wiesel själv inte skulle karakterisera sig som "budbärare från Gud" ("messenger of God"), eftersom han snarare har frågor till Gud än ett budskap från honom. Wiesel kan alltså 
inte betraktas som "profet" i biblisk mening. Likväl har han det gemensamt med vissa av de bibliska profeterna, att han riktar ett anklagande budskap mot himlen. Wiesel har inte heller funktionen av en rabbi, som söker svar och forklaringar till katastrofer som tid efter annan drabbat det judiska folket. I anslutning till Irving Greenberg betraktar Brown Wiesel som en "berättare" ("teller of tales"), som enligt honom är den nya typ av lärare som situationen efter holocaust kräver (s. 42-44).

Rubriken för det andra kapitlet är "Darkness that eclipses light (a moral journey-1)". Brown forsöker visa hur Wiesel resp. huvudpersonerna i de fyra första böckerna har rollerna som "offer" (Natten) och "skarprättare" (Gryningen), hur han/de prövar "flykten" ( $D a-$ gen) och "vansinnet" samt hur han bedömer "åskådaren" (The Town Beyond the Wall). I den sistnämnda boken bryter ljuset for forsta gången igenom, vilket återspeglas $\mathrm{i}$ rubriken till det tredje kapitlet i Browns bok: "Light that penetrates darkness (a moral journey2)". Här hjälper huvudpersonen Michael en medfånge och därmed āven sig själv att övervinna vansinnet genom att tala till honom och framtvinga en respons. Brown har rātt i a.tt denna roman bygger på Martin Bubers dialogiska princip (s. 73). Det vore värt att undersōka om inte släktskapen Buber-Wiesel ār större ān enskilda berōringspunkter som denna: t.ex. ifråga om interpretationen och användningen av hasidiska berättelser.

Den foljande romanen (The Gates of the Forest) innebär ett nytt steg bort från ensamheten ("from solitude to city") och från relationen till endast en annan: Gregor/Gavriel finner vägen till en grupp partisaner och i slutet till en liten hasidisk synagoga i New York, där han läser Kaddisch, bönen över de döda, och det är samtidigt ett bejakande av Gud och människan. I den därpå följande romanen ( $A$ Beggar in Jerusalem), som är Wiesels svåraste (så med rätta Brown, s. 100) tas steget från en "stad", vilken som helst, till Jerusalem kort efter sexdagars-kriget. Här beskriver Brown Wiesels nya genombrott "The past, which has been the enemy, can now be invoked as an ally" (s. 104) och det sker när tillträdet till klagomuren blir möjligt genom erövringen av
Östra Jerusalem. Wiesel låter nämligen galningar, tiggare, lärare, studiekamrater från sin barndom, ofta fiktiva gestalter ur sina böcker tillsammans tåga till muren för att bevittna àterföreningen av forntid och nutid, låt vara att framtiden är gåtfull.

Kap 4 i Browns bok bär igen en talande rubrik: "From Auschwitz to Mount Moriah-and return (a historical journey)". Här tar han upp Wiesels resa till sin födelsestad Sighet i Rumänien, dokumenterad i hans essäsamlingar ${ }^{5}$ och den mentala resan tillbaka till sin barndoms hasidism, till bibeln och den klassiska judendomens midrasch-litteratur. Wiesel stannar ju inte $\mathrm{i}$ det förflutna, utan återvänder till nuet och inleder en serie resor till Sovjet, Kambodja, Sydafrika etc. Kap 5 àter rubriceras som en "teologisk resa" ("The silence of God, and the necessity of contention"). Var och en som läst Wiesel vet hur han både i romaner och essäer ofta diskuterar eller låter sina huvudpersoner diskutera frågor om vad och hur man kan tro som jude efter Auschwitz: är Gud själv offer, skarprättare, åskådare, eller deltagare ("participiant"), en som delar lidandet med mānniskorna? Wiesel ger som vanligt inte svar, han frågar. Han menar i varje fall att Auschwitz är en så genomgripande händelse, att den framtvingar en total omprövning av tro och teologi.

I det sjätte kapitlet, "Birkenau and Golgotha (challenges to a Christian journey)", betraktar Brown Wiesels förhållande till kristendomen. Wiesel har sagt skarpa ord om kristendomens traditionella judehat, korståg, förfoljelser och pogromer i Kristi namn, påvens likgiltighet under andra världskriget osv. Anmärkningsvärt är samtidigt, att han också har sagt, att han inte kan hata de kristna for det. Här tar Brown sin utgångspunkt för en revision av den traditionella kristna judemissionen: "no more proselytizing of Jews by Christians, no more attempts to 'convert"' (s. 186). Han motiverar detta med två huvudargument: 1) Teologiskt är kristendomen en utsträckning av judendomen till icke-judar, en anslutning av dessa till Guds förbund med Israels folk. Judar och kristna dyrkar därför samma Gud. 2) Historiskt har så mycket förskräckligt hänt $i$ relationen kristna-judar, att det är arrogant att idag anse, att judar bör bli medlemmar 
av kristna församlingar. Brown är ju bland kristna teologer ingalunda ensam om ett sådant ställningstagande, men den kraft och klarhet med vilken det sker ār beundransvärd.

Brown ägnar ännu ett kapitel åt Wiesels fortsatta kamp för mänskliga rättigheter ("a human journey"), mot likgiltighet och glömska och ett åt hans trots-allt-attityd, en inställning som ofta kommer fram, när förtvivlan om framtiden kanske skulle vara den logiska slutsatsen av vad vi ser och hör omkring oss idag.

Vad jag finner värdefullast i Browns interpretaion av Wiesel är hans inlevelseförmåga, synbarligen stärkt av flerårigt samarbete bl.a. i presidentens holocaust-kommission. Viktiga är också hans iakttagelser av de olika faserna i Wiesels egen utveckling som överlevande och författare, samt hans aktgivande på nyckelorden i början och slutet av Wiesels böcker för att få en en nyckel till förståelsen av dem. Jag uppskattar odelat Browns egna radikala slutsatser fö sitt teologiska tänkande. Enligt min mening är hans bok ett betydande interpretativt verk och ett tankeväckande teologiskt dokument.

\section{Norska vänporträtt}

Intresset för Wiesel i Norge har redan länge varit exceptionellt starkt. Därom vittnar hans talrika besök i Norge och det faktum att antalet Wiesel-böcker i norsk översättning (13 för närvarande) så vitt mig är bekant kommer närmast efter de engelska och tyska. ${ }^{6}$ Intresset kan ses också därav att minst tre volymer om Wiesel getts ut under de tre senaste åren. Nästan samtidigt med att han mottog fredspriset utgavs på Aschehougs förlag en bok av två unga journalister, Erling B $\varnothing$ och Håkon Harket, kallad Elie Wiesel-et møte. Och redan följande år utgav samma förlag professor Gerd Høsts Kampen mot glemselen. Glimt fra ett vennskap med Elie Wiesel. Härtill får man lägga den i Nordisk Judaistik tidigare recenserade boken av Anton Blom ${ }^{7}$ som utgavs på Cappelens forlag 1987 och den norska översättningen av McAfee Browns Wiesel-bok.
$\mathrm{B} \varnothing$ och Harket skriver två delar med $16^{8}$ korta kapitel var, först en biografisk skiss (s. 11-85) och därefter en serie intervjuer genomforda i Wiesels hem i New York i november 1986 (s. 89-154). Boken upptar ett efterord av Lars Roar Langslet (s. 157-174) och avslutas med en förteckning av Wiesels böcker i original och i norsk översättning.

Som första introduktion till Wiesel är det biografiska avsnittet nyttigt och lätttillgängligt. Vill man ha en fylligare framställning är Bloms bok att föredra. Mera ger kanske intervjuerna, åtminstone om man inte råkat läsa ett antal sådana förut. Här kommer författarnas egen insats fram i de frågor de ställt, t.ex. om faran för atomkrig, mänskliga rättigheter, Israel och utsikterna för fred i Mellanöstern. Wiesel verkar på den sista punkten optimistisk, även om han inte sade mer än att han är säker på att om Israel känner sig lite mindre hotat, så kommer det att göra en gest gentemot palestinierna. Men vilken gest det kunde vara, vågade han inte uttala sig om (s. 121). Jag finner det sympatiskt, att Wiesel utan omsvep erkänner att han inte kan bedöma rent politiska spörsmål. Han säger, att han är en traumatiserad jude som inte kan förväntas ha samma hållning till det judiska folket som till andra, men att det betyder att han kräver mera av judarna och Israel än av andra.

Intervjuarna tycks mig i allmänhet vara initierade. Kanske är det brådskan som gjort att de missuppfattade Wiesel, när de på s. 123 läter honom säga "Kongen av Judea og hans menn tok fanger som gisler i Babylon". Det handlar om 500-talet före vår tideräkning, efter första templets fall, och vad Wiesel kan ha sagt ār att Juda konung och hans män då togs som gisslan och fördes till Babylon och därmed gav upphov till den första judiska exilen. Mycket initierad ār i varje fall Langslets efterskrift som ger en översiktlig interpretation av Wiesels forfattarskap. Helhetsintrycket är att $\mathrm{B} \varnothing$ och Harket gett oss en bra första bok om 1986 års fredspristagare.

Helt annorlunda är Gerd Høsts bok om Wiesel. Visserligen innehåller också den t.ex. historiska data om Sighet i Transsylvanien, liksom givetvis biografiska upplysningar om Wiesel. Men här träder det konstnärliga, skapande 
och interpretativa i förgrunden. Gerd Høst känner Wiesel mycket väl och hon känner likaså de många Wiesel-vännerna i Norge vars bakgrund och verksamhet delvis föklarar hans genomslagskraft där: skolkamraten Herman Kahan, psykiatriprofessorn Leo Eitinger, författaren Johan Borgen och Aschehougs eldsjäl, Max Tau, av vilken hon med humor och värme tecknar ett porträtt. Nära nog dråpligt är avsnittet om hur Max Tau blir heltänd på Wiesel och for denne deklarerar, att han nu personligen skall se till att "Natten" äntligen blir översatt till norska-sedan han på frågor av Gerd Høst under 60-talet anfört allehanda betänkligheter mot att ge ut ännu en bok om holocaust efter Anne Franks dagbok! Med tanke på att Gerd Høst arrangerat kulturkvällar med Wiesel $\mathrm{i}$ Trondheim och Oslo och översatt en lång rad av hans böcker, börjande med En tigger i Jerusalem (1970), kan hennes betydelse som introduktris av Wiesel i Norge svårligen överskattas.

Gerd Høst var inbjuden av Wiesel att övervara premiären för hans kantat Ani Maamin 1973 på Metropolitian i New York till musik av Darius Milhaud. Hon skildrar starkt Wiesels egen roll som berättare på scenen och det mottagande kantaten fick. Kanske allra mest gripande är dock hennes skildring av holocaustkommissionens besök i Warszawa, Auschwitz, Treblinka, Babij Jar och Moskva i augusti-september 1979. Hon var själv med som korrespondent för Dagbladet. Wiesel uppträder suveränt som tolk och talesman för kommissionen, samtidigt som han är lika skakad i sin själ som någon av de andra deltagarna. Men hon följer inte bara Wiesels forehavanden, hon ser, hör och tolkar de andras reaktioner genom anekdoter och egna dikter. Bokens dokumentära och konstnärliga karaktär förstärks med talrika fotografier. Om man härtill lägger att trycket och layouten är förträffliga, är det sagt att Gerd Høsts bok är en sådan som man önskar att skulle komma $\mathrm{i}$ allas händer som inte bara vill lära känna Wiesel utan komma honom nära, älska och förstå honom.

\section{En veritabel källa}

Irving Abrahamsons utgåva av Wiesels småskrifter i tre volymer är en märkeshändelse. Against Silence: The Voice and Vision of Elie Wiesel utkom år 1985 på Holocaust Library i New York och omfattar 1188 sidor. Utgivarens introducerande essä sträcker sig redan över drygt 70 sidor och koncenterar sig främst på Wiesels litterära verksamhet. Wiesels småskrifter disponeras i 21 olika sektioner, börjande med artiklar och föredrag om holocaust, då och nu, och slutande med ett plenarföredrag vid en internationell konferens i New York i maj 1984. Däremellan placeras en mängd inlägg av varierande form och innehåll. Inom varje sektion kommer bidragen i kronologisk ordning. Flertalet har publicerats förut, men en del föredrag och anförande finns nu första gången i tryck.

Till svårigheterna har hört att hitta en genomgående indelningsgrund: enligt teman eller enligt genrer är de båda huvudalternativen. I en inledande anmärkning förklarar Abrahamson att delarna I och II är disponerade efter teman, medan sektionerna i del III är disponerade efter genrer, auditorier och uttalanden av Wiesel om sig själv. Det betyder att vi i band III kan läsa korta stories publicerade av Wiesel, kommentarer av honom med anledning av tillkomsten och publiceringen av hans böcker, oppna brev, tal inför presidentens holocaustkommssion m.m. I delarna I och II där indelningen är tematisk, står de mest olika former sida vid sida. Men detta innebär inga större svårigheter för läsaren, när man väl blivit medveten om avsikten.

Ett par anmärkningar vill jag rikta mot de rätt omfattande bibliografierna i verket. De är två till antalet, en efter utgivarens introducerande essä i band I och en i slutet av band III, avsedd för hela arbetet. Det finns emellertid ingen samlande bibliografi over Wiesels arbeten eller över vad som skrivits om honom, $i$ original eller t.ex. i engelsk översättning. Vi făr alltså ānnu nöja oss med bibliografier i urval, för bestämda ändamål. Abrahamsons arbete är inte i sig heller avsett som en bibliografi utan som en textutgåva. Men ändå hade jag väntat någon form av samlande bibliografi. Vidare 
har jag ej blivit på det klara över vilka kriterierna for urvalet av småskrifter varit. På s. 371f i band III förtecknas ett antal "Other sources" dvs andra källor for Wiesels småskrifter ān de tidigare i samma band nämnda. Här förtecknas en rad artiklar i samlingsvolymer av olika slag och dessa artiklar är också intagna i Abrahamsons utgåva på olika ställen-med fyra undantag. Har utgivaren helt enkelt inte fätt tillåtelse av ta med också dessa fyra? Något annat skäl att utelämna dem kan jag inte se.

Också med smärre brister som de nämnda är det klart att Abrahamsons tre volymer innebär en enorm förbättring av våra möjligheter att läsa "hela Wiesel". Både den hängive läsaren av hans romaner och essäer och den som vill forska i Wiesel kommer för eller senare att bli intresserad av hans småskrifter, inlägg och kommentarer till världshändelserna och sin egen verksamhet. Också Wiesel som recensent av andra är ett intressant kapitel, likaså är det av vikt att veta, var han publicerat sig. Sådant kan Abrahamson hjälpa oss med som ingen annan.

\section{Wiesel själv}

Vaksamheten i Norge beträffande Wiesel kom tydligt fram igen, när hans senaste roman utkom i början av 1987. Redan samma år förelåg en norsk översättning av Gerd Høst: Tusmørket $i$ det fjerne. ${ }^{9}$ Det är kanske mer än en tillfällighet att förlaget (Aschehoug) samma år gav ut en nyupplaga av Lise Houms norska version av Wiesels fjärde bok, som var den första som översattes till norska (redan 1964): Lykkens by. ${ }^{10}$ Det finns nämligen en rad beröringspunkter mellan dessa romaner.

Om vi följer McAfee Browns metod att ge akt på begynnelserna, kan vi genast anteckna: 1. Lykkens by har som motto Dostojevskij-citatet "Jeg har ett mål: å bli gal" och Tusmørket i det fjerne ett motsvarande från Maimonides: "Verden ville icke ha eksistert uten de gale". 2. Boken inleds med satsen: "Ute har tusmørket lagt sig over byen som en voldsmanns tunge hånd", medan den nya romanen har "Tusmør- ket" redan i titeln. Detta ordpar dominerar också i fortsättningen: det hotande eller redan frambrutna vansinnet hos de överlevande från holocaust, och dess metafor, skymningen. Det finns ännu några andra likheter: Pedro är namnet på huvudpersonens Michaels goda vän och medhjälpare i Lykkens by. Pedro är föremålet for huvudpersonen Raphaels efterforskningar $i$ Tusmørket. Och vänskapen förläggs till efterkrigsåret 1945, då Pedro i den första boken hjälper Michael att àtervända till sin hemstad i Ungern, i den senare hjälper han Raphael att hitta sin tillfångatagne bror på ett mentalsjukhus bakom järnridån. Man kunde hitta andra likheter, men låt oss i stället ta fasta på det som skiljer, dvs det som gör den andra boken till något nytt.

Vi är i Tusmørket inte längre kvar i efterkrigstidens Europa, utan har flyttat oss till 80-talets USA. Raphael Lipkin, en överlevande polsk jude som forlorat sin familj i holocaust, verkar som universitetsprofessor i New York. Han blir uppringd av en anonym person som sāger sig ha uppgifter om Pedro, ofordelaktiga uppgifter till skillnad från den bild av Pedro som Raphael gett i en av sina böcker. Raphael vägrar tro den anonymes påståenden om att Pedro, som kommit i rysk krigsfångenskap, skulle ha fungerat som angivare i fängelset: tre kamrater forsvann efter lika många förhör med Pedro. Han vill behålla och behåller sin bild av Pedro som den helt osjälviske vännen, som utsatte sig för vilka faror som helst för att rädda en vän. Men den anonyme insinuerar, att Raphael kunde få veta mera på ett mentalsjukhus i närheten och universitetsprofessorn ägnar sina sommarferier åt "biblioteksarbete" på detta sjukhus, för att få veta om Pedro själv är där eller den anonyme, eller någon annan som kunde veta något om hans förlorade vän.

Berättelsen oscillerar mellan sjukhusmiljön, Raphaels uppväxt i Polen, den korta samvaron med Pedro efter kriget. Många självbiografiska drag ingår som vanligt hos Wiesel, t.ex. studierna i Paris och universitetsmiljön i New York. Intervjuerna med de sjuka får illustrera Wiesels fascination av de galna, vansinniga, lidande människorna, ofta men inte så mycket i denna bok med bakgrund i holocaust. De identifierar sig i regel med en biblisk gestalt: 
en är Adam, en annan Kain, en tredje Abraham, en fjärde Josef, en femte Jeremia och två olika (en jude och en kristen) Messias. Själv kānner Raphael stor sympati för dem, är hela tiden osāker huruvida han själv håller på att bli eller redan är en av dem.

Karakteristiskt för Wiesel är nu som alltid frågorna kring Gud och hans roll i holocaust. Hos Wiesel är det inte fråga om teodicéproblemet $\mathrm{i}$ dess klassiska utformning. Inte ett försvar för Gud eller ett rättfärdigande av hans handlingar. Det är själva gåtan som varje troende ställs inför: hur skall det förklaras, hur går det som skedde ihop med min fäderneärvda tro på Gud? En grym Gud eller vad som är värre en likgiltig Gud? (så t.ex. s. 240f). Som vanligt får vi inga svar, åtminstone inte direka eller definitiva. Raphael frågar Pedro i ett av deras mentala samtal oberoende av tid och rum: "Tror du som jeg at man må være gal for i våre dager å tro på Gud?" Pedro svarar: "Om det nå var Gud som var gal?" (s. 242). Och i slutet när Raphael håller på att lämna sjukhuset träffar han en gammal patient, som påminner om den gamle sinnesjuke från hans barndoms stad, som ville hjälpa judarna under den tyska ockupationen. Men vem är han egentligen-Gud själv? Människorna lider, ja, och man må ropa ut sitt lidande, men inte för sig själv utan för nästan och "för mig", dvs. den gamle, alltså Gud? Också han lider nämligen och mest av alla, men detta Guds lidande tar inte bort mitt eller andras, tror Raphael. Och Gud (?) bekräftar: "Ingen får fullmakt til å lide. Man hverken lever eller dør i nestens sted." Inte ens Gud, inte heller Pedro. Och Gud kan ej heller hjälpa Pedro, ty "Ingen har fullmakt til å frelse" (s. 245).

Men denna resignation är ännu inte slutet. Den gamle ville så gärna träffa Raphael, för, säger han med ett leende: "Jeg liker historier" (s. 247). Och Raphael själv är skrämd av de galna men än mera av dem som driver honom in i galenskapen (s. 249). Den gamle i hans hemby hade slocknade ögon, men det ansikte han tar med sig från skymningen kring hospitalet har "uendelig kloke og mennesklige øyne som tvinger sannheten frem i en verden av løgner, har ikke lenger et sluknet blikk" (s. 250). Alltså resignation, när det gäller att be- svara omöjliga frågor, men inte när det gäller att kämpa för sanning mot lögn, för engagemang och medlidande mot det största onda: likgiltigheten.

En mycket wieselsk roman, vilket redan är ett kvalitetsomdöme. Dock inte hans allra starkaste, som enligt min bedömning är Från en mördad judisk poet. Ett Testamente, som for övrigt också uppvisar beröringspunkter med denna roman. Tag och läs.

\section{BIBLIOGRAFI}

Här följer en förteckning över Wiesels skrifter och ett urval av litteraturen om honom. Av de forra fortecknas originalutgåvorna, varefter foljer i nämnd ordning översättningarna till engelska, danska, norska, svenska och finska, likaså i första utgåva. ${ }^{11} \mathrm{Av}$ den senare tar jag med endast de arbeten som jag känner till eller annars har uppgifter om och efterstrāvar alltså ingen fullständighet.

\section{Självbiografi:}

La Nuit. Paris: Éditions du Minuit, 1958.

Night. New York: Hill and Wang, 1960.

Natten. København: Samleren, 1987.

Natten. Oslo: Aschehoug, 1971.

Natten. Stockholm: Forum, 1972. ${ }^{12}$

\section{Fiction:}

L'Aube. Éditions du Seuil, 1960.

Dawn. NY: Hill and Wang, 1961.

Daggry. København: Samleren, 1987.

Daggry. Oslo: Aschehoug, 1976.

Gryningen. Stockholm: Forum, 1973.

Le Jour. Paris: Éditions du Seuil, 1961.

The Accident. NY: Hill and Wang, 1962.

Dagen. København: Samleren, 1987.

Dagen. Oslo: Aschehoug, 1977.

Dagen. Stockholm: Forum, 1974.

La Ville de la Chance. Éditions du Seuil, 1962.

The Town Beyond the Wall. NY: Holt, Rine- 
hart and Winston, 1964.

Lykkens by. Oslo: Aschehoug, 1964.

Les Portes de la Forêt. Paris: Éditions du Seuil, 1964.

The Gates of the Forest. NY:Holt, Rinehart and Winston, 1966.

Le Mendiant de Jérusalem. Paris: Éditions du Seuil, 1968.

A Beggar in Jerusalem. NY: Random House, 1970.

Tigger $i$ Jerusalem. København: Samleren, 1970.

En tigger $i$ Jerusalem. Oslo: Aschehoug, 1970. Tiggaren i Jerusalem. Stockholm: Gummessons, 1971.

Le Serment de Kollvilàg. Paris: Éditions du Seuil, 1973.

The Oath. New York: Random House, 1973. Eden fra Kollvillàg. Oslo: Aschehoug, 1974. Löftet i Kollvillàg. Stockholm: Forum, 1975.

Le Testament d'un Poete Juif Assasiné. Paris: Éditions du Seuil, 1980.

The Testament. New York: Summit Books, 1981.

Testamentet. Oslo: Aschehoug, 1981.

Från en mördad judisk poet. Ett testamente. Stockholm: Atlantis, 1983.

Le Cinqueime Fils. Paris: Éditions Grasset \& Fascuelle, 1983.

The Fifth Son. NY: Summit Books, 1983.

Den femte sønn. Oslo: Aschehoug, 1984.

Den femte sonen. Stockholm: Atlantis, 1985.

Le Crépuscule, au loin. Éditions Grasset \& Fascuelle, 1987.

Tusmørket $i$ det fjerne. Oslo: Aschehoug, 1987.

Skådespel:

Zalmen ou La Folie de Dieu. Paris: Éditions du Seuil, 1968.

Zalmen, or the Madness of God. NY: Random House, 1974.

Ani Maamim: A Song Lost and Found Again. NY: Random House, $1973 .^{13}$

Le Procès de Shamgorod (tel qu'il se deroula le 25 fevrier 1649). Paris: Éditions du Seuil, 1979.

The Trial of God. A Play in three acts. NY: Random House, 1979.
Essäer:

Chants des Morts. Paris: Éditions du Seuil, 1966.

Legends of Our Time. New York: Holt, Rinehart and Winston, 1968.

De dødes sang. Oslo: Aschehoug, 1980. ${ }^{14}$

Entre Deux Soleils. Paris: Éditions du Seuil, 1970.

One Generation After. NY: Random House, 1970.

Un Juif Aujourd'hui. Paris: Éditions du Seuil, 1978.

A Jew Today. NY: Random House, 1978.

Signes d'Exode: essais, histories, dialogues.

Paris: Éditions Grasset \& Fasquelle, 1985.

\section{Hasidismen:}

Célébration hassidique. Paris: Éditions du Seuil, 1972.

Souls on Fire. Portraits and Legends of Hasidic Masters. NY: Random House, 1972.

Den evige glød: chassidiske portrøtter og legender. København: Samlerens Bogklub, 1972.

Den hellige glød. Oslo: Aschehoug, 1973.

Porträtt och legender. Stockholm: Atlantis, 1978.

Four Hasidic Masters and Their Struggle Against Melancholy. Notre Dame, Indiana: University of Notre Dame Press, 1978.

Contre la Melancolie: Célébration hassidique II. Paris: Éditions du Seuil, 1981.

Paroles d'étrangers. Paris: Éditions du Seuil, 1982.

Somewhere a Master. NY: Summit Books, 1982.

Bibeln:

Célébration biblique. Paris: Éditions du Seuil, 1975.

Messengers of God. Biblical Portraits and Legends. NY: Random House, 1976.

Guds utkorade. Bibliska gestalter i skriften och i sägnerna. Göteborg: Stegeland, 1977.

Images from the Bible. Woodstock, NY: The Overlook Press, 1980. 
Cinq Portraits bibliques. Paris: Éditions du Seuil, 1980.

Five Biblical Portraits. Notre Dame: University of Notre Dame Press, 1981.

Portretter. Oslo: Ansgar forlag, 1986.

Dokument:

Les Juifs du silence. Paris: Éditions du Seuil, 1966.

The Jews of Silence: A Personal Report on Soviet Jewry. Transl. from the Hebrew with an Historical Afterword by Neal Kozodoy. NY: Holt, Rinehart \& Winston, 1966.

Tavshedens $j ø d e r$. København:

Samleren, 1987.

De tause jøder. Oslo: Aschehoug 1969.

Hiljaisuuden juutalaiset. Tampere:

Shalom 1986.

\section{Artiklar och småskrifter: ${ }^{15}$}

Talking and Writing and Keeping Silent. The German Church Struggle and the Holocaust. Ed. by Franklin H. Littel and Hubert G. Locke. Detroit: Wayne State University Press, 1974, 269-277.

The Holocaust and the Future. The Holocaust: Its Meaning for Christians and Jews. St Louis: National Conference of Christians and Jews, 1976, 7-16.

Wiesel, E. m.fl. (ed.), Dimensions of the Holocaust. Evanston: Northwestern University Press, 1978.

Why I Write. Confronting the Holocaust: the Impact of Elie Wiesel. Ed. by Alvin H. Rosenfeld and Irwing Greenberg. Bloomington: Indiana University Press, 1978, 200-206.

Why I Remember? Vancouver (B.C.) Jewish Western Bulletin, 14. Dec. 1978, 25-32.34.

Why Should People Care? Prologue. A Consuming Fire: Encounters with Elie Wiesel and the Holocaust. By J.K. Roth. Atlanta: John Knox Press, 1979.

Wiesel, E. (ed.), The Golem. The Story of a legend. NY: Summit Books, 1983.

In the Footsteps of Shimon Dubnov. The Antisemitism in Our Time: A Threat Against Us All. Ed. by Leo Eitinger. Oslo: The Nansen Committee, 1984, 141-152. ${ }^{16}$

Against Silence: The Voice and Vision of Elie Wiesel. Ed. by I. Abrahamson. 3 vols. New York: The Holocaust Library, 1985.
Lebensstationen. Kirche und Israel. Neukirchener Theologische Zeitschrift, Jhg 2, 1987:1, 56-68.

\section{Nobelföredraget:}

Håp, fortvilelse og erindring. Kirke og Kultur. 1986: 584-590 (övers. Kjetil Hafstad); och A. Blom, Elie Wiesel og ansiktet $i$ vinduet. Oslo: J.W. Cappelens forlag, 1987, 225-234 (övers. Oskar Mendelsohn).

\section{Litteratur om Wiesel (i urval):}

Aarvik, E., Elie Wiesel-en menneskehetens menneske. Kirke og Kultur, 1986, 578-583.

Abrahamson, I., Introductory Essay, Against Silence. Ed. by I. Abrahamson, Vol. I, 9-83. Abramowitz, M., Elie Wiesel: A Bibliography. Metuchen, NJ: The Scarecrow Press, 1974.

Batstone, D.B., The Transformation of the Messianic Idea in Judaism and Christianity in the Light of the Holocaust: Reflections on the Writings of Elie Wiesel. Journal of Ecumenical Studies, 24:3 (1986), 587-600.

Berenbaum, M., The Vision of the Void: Theological Reflections on the Works of Elie Wiesel. Middletown, CT: Wesleyan University Press, 1979.

Blom, A., Elie Wiesel og ansiktet $i$ vinduet. Oslo: J.W. Cappelens Forlag, 1987.

McAfee Brown, R., Elie Wiesel: Messenger to All Humanity. Notre Dame: University of Notre Dame Press, 1983.

Norsk overs: Elie Wiesel: menneskehetens budbringer. Oslo: Ansgar forlag, 1985.

Bø, E. \& Harket, H., Elie Wiesel, et møte. Oslo: Aschehoug 1986.

Cargas, H.J., Harry James Cargas in Conversation with Elie Wiesel. New York: Paulist Press, 1976.

Cargas, H.J., An Interview with Elie Wiesel. Holocaust and Genocide studies, vol I:1 (1986), 5-10.

Cargas, H.J. (ed.), Responses to Elie Wiesel. Critical Essays. New York: Persea Books, 1978.

Cedars, M.M., Silence against Silence: the two voices of Elie Wiesel. Cross Currents 36, 1986, 257-266. 
Friedman, M., Abraham Joshua Heschel and Elie Wiesel, You Are My Witnesses.

New York: Farrar, Straus, Giroux 1987.

Frost, C.J., Religious Melancholy or Psychological Depression? Some Issues involved in relating psychology and religion as illustrated in a study of Elie Wiesel. Lanham, Md: University Press of America, 1985.

Høst, G., Kampen mot glemselen. Glimt fra et vennskap med Elie Wiesel. Oslo: Aschehoug: 1987.

Koppel, G. \& Kaufmann, H. (ed): Elie Wiesel: A Small Measure of Victory. Tucson: University of Arizona Press, 1974.

Langer, L.L., Versions of Survival. The Holocaust and the Human Spirit. Albany: State University of New York Press, 131-190.

Robbins, J.K., The Negative Theodicy of Elie Wiesel. Dialog, 26, Spring 1987, 131-133.

Rosenfeld, A.H. \& Greenberg, I. (ed), Confronting the Holocaust. The Impact of Elie Wiesel. Bloomimgton: Indiana University Press 1978. Roth, J.K., A Consuming Fire: Encounters with Elie Wiesel and the Holocaust. Atlanta, Ga: John Knox Press, 1979.

Stern, E.N., Elie Wiesel: Witness for Life.New York: Ktav, 1982.

Tysk övers: Wo Engel sich versteckten. Das Leben des Elie Wiesel, Freiburg: Herder Verlag, 1986.

Walker, G.B., Elie Wiesel: A Challenge to Theology. Folkestone: McFarland, 1987.

\section{NOTER}

1. Se t.ex. Wiesels föredrag Lebensstationen, hållet vid Evangelische Akademie Loccum, BRD, i maj 1986, och publicerat i Kirche und Israel, Jhrg 2, Nr 1 (1987), 64. 2. Jfr Karl-Johan Illman, Den teologiska holocaustlitteraturen, Nordisk Judaistik vol. 4, $\mathrm{nr} 1$ (1982), 23-29. 3. Eugen Kogon, Johann Baptist Metz (hrsg), Gott nach Auschwitz. Dimensionen des Massenmords am jüdischen Volk. Freiburg, Basel, Wien: Herder Verlag (2. Auf), 1981, 138. Detta band innehaller artiklar förutom av utgivarna av Wiesel, Lucy S. Dawidowicz,
Dorothy Rabinowitz och Robert McAfee Brown.

4. Notre Dame, London: University of Notre Dame Press, 1983, 244s. Boken är även översatt till norska, se bibliografin.

5. Jfr bibliografin.

6. Antalet böcker på franska (mestadels original) är enligt ovanstående förteckning 23, antalet böcker på engelska är likaså 23 eller 24, om den senaste romanen är översatt, vilket jag förmodar men inte kunnat bekräfta. De tyska översättningarna var i okt. 198718 till antalet, enligt en förteckning i Kirche und Israel Jhrg 2, Nr 2 (1987), 195. Ovanstående bibliografi upptar 9 svenska, 7 danska, och 1 finsk översättning!

7. Elie Wiesel og ansiktet i vinduet. Oslo: Cappelen, 1987, recenserad av mig i Nordisk Judaistik, 9, no 1 (1988), 66-67.

8. Kap XVI i den första delen bär oriktigt siffran XVIIen indikation på hastig tillkomst.

9. Oslo: Aschehoug 1987, 254 s., inkluderande en förteckning av judiska ord och uttryck sammanställd av professor Leo Eitinger. Original: Le Crépuscule, au loin. Paris: Éditions Grasset \& Fasquelle, 1987.

10. Oslo: Aschehoug 1987. Original: La Ville de la Chance, Paris: Éditions du Seuil, 1962.

11. I några fall har jag inte uppgift om original eller första upplagan i översättning och har därvid förtecknat den första utgåvan jag känner till. För uppgifter om original och översättningar tackar jag Første bibliotekar Ulf Haxen (Köpenhamn), professor Gerd Høst (Oslo) och Dr.phil. Hilde Rohlén-Wohlgemuth (Stockholm).

12. Wiesels tre första böcker har sedermera utgivits som trilogi på bl.a. engelska norska och svenska: The Night Trilogy. Night, Dawn, Day. NY: Hill and Wang, 1985. Natten, Daggry, Dagen. Oslo: Aschehoug 1986. Natten, Gryningen, Dagen. Stockholm: Forum 1985.

13. Denna utgåva är tvåspråkig, fransk och engelsk.

14. Denna utgåva innehåller material även ur de följande essäsamlingarna.

15. De flesta ingår i Abrahamsons trevolymers utgåva och här förtecknas sådant som av en eller annan anledning inte upptagits där.

16. Ingår i kortare form i Abrahamson, Against Silence, vol I, 115-121.

11.7. 1988 


\section{SUMMARY}

This article focuses on some recent books about Elie Wiesel, a three volume edition of his articles and minor writings, and his latest novel.

Robert McAfee Brown's book Elie Wiesel: Messenger to All Humanity (University of Notre Dame Press, 1983) is considered to be a remarkably sensitive interpretation of Wiesel and a very helpful guide to his literary work. In addition to this it offers a bold revision of some theological issues from a Christian perspective, e.g. the Jewish-Christian relationship.

Then two Norwegian books on Wiesel are considered. Erling Bø's and Håkon Harket's Elie Wiesel-et møte (Elie Wiesel-an encounter, Aschehoug 1986) was written in the short period between the announcement that Wiesel would receive the Nobel prize for peace and his actual reception of it in December 1986. It is considered to be a good first introduction, although it is too scetchy to help those who want to get a thorough knowledge of him. Here another book makes up a great deal, namely Gerd Høst's Kampen mot glemselen. Glimt fra et vennskap med Elie Wiesel (The struggle against forgetfulness. A glimpse from a friendship with Elie Wiesel, Aschehoug 1987). The authoress has translated several of Wiesel's books into Norwegian, arranged evenings with lectures of Wiesel in Norway, accompanied him and the other members of the United States Holocaust Comittee on a journey to the holocaust cites in Eastern Europe in 1979. She not only describes events such as these, but also gives the background picture for Wiesel's popularity in Norway, which is astonishing indeed. A very fine book, by all criteria.

Irwing Abrahamson's edition Against Silence: the Voice and Vision of Elie Wiesel (The Holocaust Library, 1985) in three volumes is a most welcome tool for all who do reserch on Wiesel or who just like to read what is otherwise scattered over a host of periodicals, newspapers and the like. And much is published here for the first time. The reviewer wonders, however, why the editor has not at the same time taken the trouble to give us a complete or near complete bibliography of Wiesel's works and why he has not printed all of Wiesel's articles here.

Wiesels most recent novel, Le Crépuscule, au loin (1987) in its Norwegian transl. (Tusmørket i det fjerne, Aschehoug 1987), is compared to his fourth book (third novel), namely La Ville de la Chance (Lykkens by, Aschehoug 1964 and 1987) and some obvious parallels and similtudes concerning motifs ("madness"), persons ("Pedro") and expressions are noted. The time perspective is another, however, fourty years after the holocaust, and the scene is now America, not Hungary. The novel, however, is very wieselian in its blend of holocaust themes and scenes with the survivors continuing efforts to come to grip with their haunting memories, the shattering of their faith, and the afterworld's way of relating to them. 